\title{
Movements of translocated captive-bred and released Critically Endangered kaki (black stilts) Himantopus novaezelandiae and the value of long-term post-release monitoring
}

\author{
Yolanda VAN HeEZIK, Richard F. MALONEY and Philip J. Seddon
}

\begin{abstract}
Translocation outcomes for mobile species can be affected by post-release movement of individuals, yet few population reintroduction and supplementation projects consider propensity to move as a selection criterion when selecting individuals to release or sites for release. We investigate the influence of release age (juvenile or subadult), the size of the release group and the size of the wild population at the release site on movements of Critically Endangered kaki (black stilt) Himantopus novaezelandiae. Over 460 subadult and juvenile kaki have been released during 12 years at nine sites in the Waitaki Basin, New Zealand, with the aim of supplementing specific sub-populations. Among the survivors that reached breeding age, $32 \%$ of released kaki ended up away from their release sites, i.e. away from the subpopulations they were intended to augment and $15 \%$ of these birds were in unmanageable areas where monitoring cannot take place. Kaki released as juveniles (2-3 months) made more long moves and moved further from the release site during 2 months postrelease. The presence of conspecifics affected behaviour after release: released birds were more likely to remain closer to the release site when the size of the wild population at the release site was large, and kaki released in larger groups were more likely to make more longer moves. Despite initial differences in mobility, long-term monitoring revealed equal proportions of 2-year old survivors that had been released as juveniles and subadults returning and being observed consistently at release sites, emphasizing the value of long-term monitoring in informing release strategies for population restorations.
\end{abstract}

Keywords Himantopus novaezelandiae, kaki, mobility, monitoring, movements, New Zealand, restoration, supplementation

\section{Introduction}

7 ranslocations of wild and captive-bred or captive-reared 1 animals are carried out as a conservation management

Yolanda van HeeziK (Corresponding author) and Philip J. SeddoN Department of Zoology, University of Otago, PO Box 56, Dunedin, New Zealand. E-mail yolanda.vanheezik@stonebow.otago.ac.nz

Richard F. Maloney* Department of Conservation, Twizel, New Zealand.

${ }^{\star}$ Current address: Research, Development and Improvement Division, Department of Conservation, Christchurch, New Zealand.

Received 4 July 2008. Revision requested 12 August 2008.

Accepted 2 October 2008. tool to reintroduce new populations in areas of historical range or to supplement existing populations for demographic or genetic benefits (IUCN, 1998), and success is typically measured in terms of the survival of founders (Seddon, 1999). However, survival per se does not necessarily assure success if survivors fail to breed or augment a target population. Long-distance post-release movements may undermine translocation objectives if surviving animals end up in inappropriate areas where they are unable to breed or do not benefit populations in need of augmentation (Skjelseth et al., 2007). Significant movements away from the release site have been recorded in a number of translocation projects: wolves Canis lupus (Fritts et al., 1984), palila Loxioides bailleui, a Hawaiian honeycreeper (Fancy et al., 1997), noisy miners Manorin melanocephala (Clarke \& Schedvin, 1997), California ground squirrels Spermophilus beecheyi (Van Vuren et al., 1997), carnivores (Miller et al., 1999) and swift foxes Vulpes velox (Moehrenschlager \& Macdonald, 2003).

Mobile species are continuously faced with the option of remaining where they are or taking a risk and leaving to search for better conditions or opportunities elsewhere (Stenseth \& Lidicker, 1992). Much of the intraspecific variation in natal and breeding dispersal in animals can be explained by individual differences in physiological (Snoeijs et al., 2004; Haag et al., 2005), morphological and behavioural traits (Aragón et al., 2006; Skjelseth et al., 2007). Propensity to disperse appears to be condition dependent and triggered by clues such as resource availability/quality, population density, social interactions with the existing population as well as other members of the release group, and interspecific interactions such as predation, competition and parasitism (Stenseth \& Lidicker, 1992; Ims \& Hjermann, 2001; Skjelseth et al., 2007).

Reintroduction practitioners must consider causes of post-release movements, as well as impacts of movements on population dynamics, spatial synchrony and population genetics, if their aim is to establish self-sustaining populations existing in an optimal spatial distribution within a manageable landscape. Post-release movements away from release sites do not fit with classic definitions of natal or juvenile dispersal. Instead, individuals are forced to orient themselves in a new area while recovering from capture and transport and, in the case of captive-bred individuals, make 
the transition to a wild existence. In this situation traditional thinking about triggers of dispersal may not apply or, if they do, they may be only some of a suite of factors influencing decisions and movements after release. Nonetheless, if propensity to move affects outcomes of population restorations, then it is important to understand which types of individuals move away from a release site, why they move, whether they end up in useful places and how this knowledge can be effectively incorporated into a reintroduction strategy.

In some cases, mobility may be an undesirable attribute to be minimized by releasing certain individuals or following protocols associated with reduced post-release movements if the goal is to supplement particular populations. Alternatively, it may be a desirable attribute to be exploited if the project relies on released animals spreading from release sites to recolonize historic ranges, thereby reducing the risk of population extinction because of local catastrophic events and promoting genetic diversity by allowing contact with remaining native populations or less related individuals (Holm et al., 2003; Kramer-Schadt et al., 2004; Trakhtenbrot et al., 2005; Matson et al., 2006; Schiegg et al., 2006). Understanding post-release movements can guide decisions about the number and spatial configuration of release sites and release protocols and should be built into management plans for reintroduction projects (Trakhtenbrot et al., 2005; Matson et al., 2006; Schiegg et al., 2006). Few projects have included propensity to move as a selection criterion when selecting individuals for release.

In the case of the Critically Endangered black stilt or kaki Himantopus novaezelandiae (IUCN, 2008), which has a small intensively managed wild population ( 72 adults, 122 juveniles and subadults in 2006) spread over a wide area (c. $7,500 \mathrm{~km}^{2}$ ), the goal of releases is to supplement small, spatially distinct subpopulations. This will increase effective population size and thereby reduce effects of demographic stochasticity as well as the risk of hybridization with pied stilts Himantopus himantopus leucocephalus because of unbalanced sex ratios at low population sizes (Pierce, 1996; Maloney \& Murray, 2001). Released birds that survive but move away from existing subpopulations into isolated areas are effectively dead in terms of their contribution to supplementation objectives because in the absence of control of introduced mammalian predators (removal by trapping), which is focused around existing subpopulations, breeding success in the wild in the Waitaki Basin is $<_{1} \%$ (Maloney \& Murray, 2001). Moreover, the difficulty in monitoring these sites means these survivors do not contribute eggs to the captive-rearing programme. The success of kaki restoration efforts has largely been because of collection of eggs from wild pairs, with artificial incubation and rearing to circumvent the period of greatest mortality (Keedwell et al., 2002).

Egg collection and captive rearing have resulted in releases of increasingly large numbers of birds; this should enhance the likelihood of population establishment and persistence (Griffith et al., 1989). A further increase in output was achieved by releasing groups of both juveniles (2-3 months from hatch) and subadults (9 months from hatch). Releasing birds as juveniles frees up space in rearing facilities, allowing greater numbers of birds to be released. Wild young birds ordinarily remain with parents until 9 months of age (Pierce, 1982), with natal dispersal occurring after independence. The consequences of releasing captivereared kaki at an earlier age than they would normally be independent are unknown. Reintroduced juveniles in several bird species made longer moves than adults (Allen et al., 1993; Reed et al., 1998; Sanchez-Lafuente et al., 2001). If this was the case in kaki they could end up leaving the populations they were intended to augment and thus undermine any gains achieved by releasing greater numbers of birds.

Here we investigate how release age may influence translocation outcomes by influencing post-release movements. We examine movements of kaki within 2 months post-release to determine (1) whether differences exist between juveniles and subadults in the lengths of moves they make and (2) whether social factors including release group size and the size of the wild population at release sites influence their mobility. Translocated birds have demonstrated higher site fidelity when wild conspecifics are present at the release site (Carrie et al., 1999; Clarke et al., 2002; Tweed et al., 2003).

Because movements of kaki are monitored in the long term, it was also possible to investigate whether any differences observed during the first 2 months after release have long-term consequences by affecting where birds eventually end up breeding at 2 years of age.

\section{Methods}

\section{Study area}

Kaki are resident in the Waitaki Basin (c. $7,500 \mathrm{~km}^{2}$ ) of South Island, New Zealand, which comprises five lakes and 10 rivers that drain three catchments, as well as areas of ponds and wetland (Fig. 1). Kaki use braided river habitat, heavily vegetated swamps, shallow tarns and river deltas for breeding and feeding (Pierce, 1996). Despite habitat destruction there is no limitation to feeding habitat availability within the basin, although flooded rivers or frozen ponds may result in local unavailability, resulting in moves to nearby habitats.

Kaki are solitary nesters and exhibit high site fidelity, with the same nesting locations often used from year to year. Pair bonds are formed soon after the break-up of the family unit in late winter (c. 9-10 months of age) but newly formed pairs do not occupy permanent sites or lay eggs until the following year, when they are 2 years old (Pierce, 1982). Pair bonds are maintained throughout the year but not necessarily from year to year (Pierce, 1982). Longevity is 6-9 years (Maloney \& Murray, 2001). Kaki are managed in 


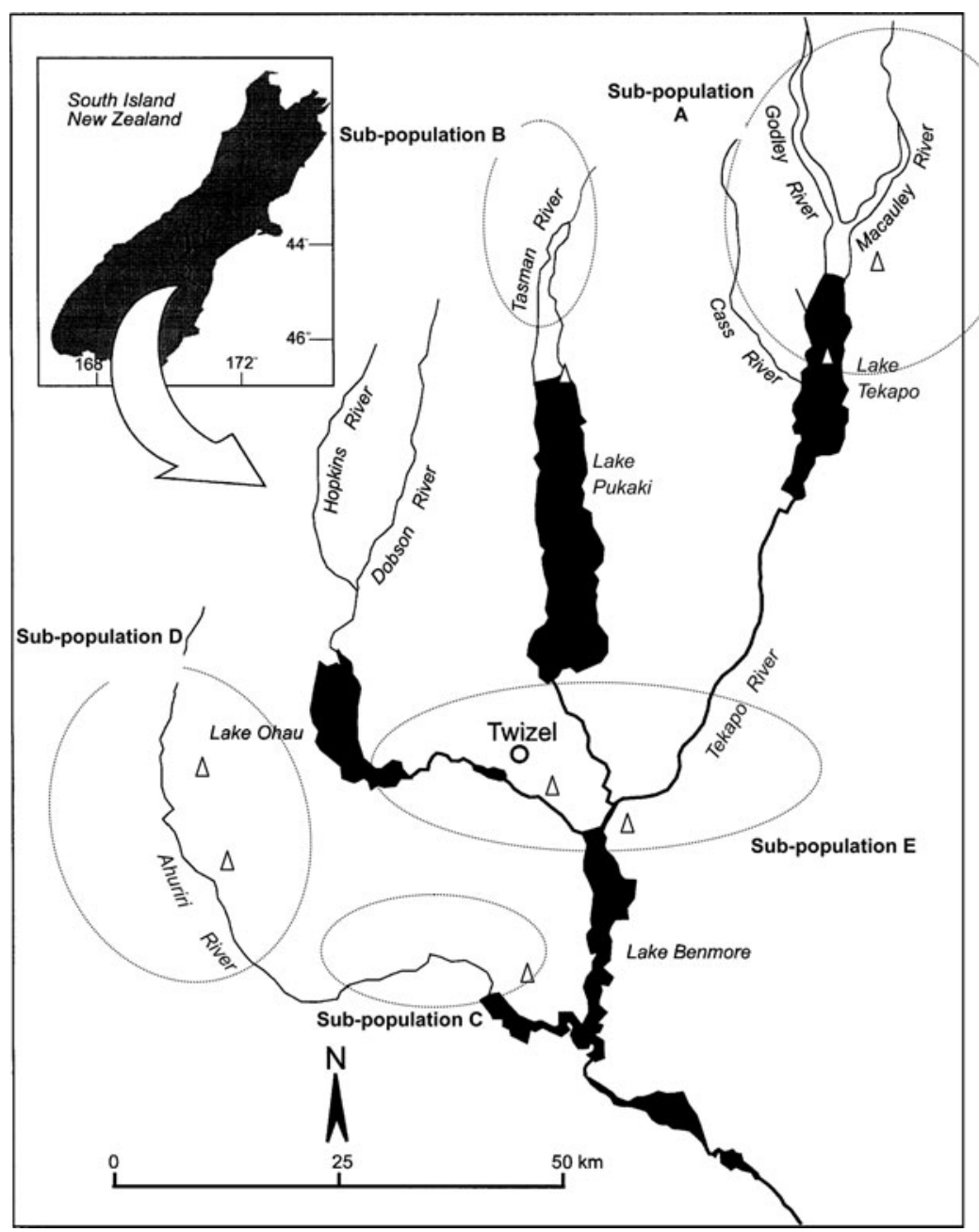

Fig. 1 The Waitaki Basin indicating areas occupied by kaki subpopulations (within ovals). five 'useful' subpopulations, i.e. accessible for predator control and monitoring (Fig. 1). Likelihood of movements by adults between these populations is low (Sanders, 1996). Additional birds frequent areas that are either outside the Waitaki Basin or unmanageable (classified as 'other').

\section{History of releases}

Eggs collected from wild and captive birds are incubated in captivity and young birds are released back into the wild either as juveniles (c. 60-90 days of age) or as subadults (c. 9 months; Maloney \& Murray, 2001). Initial releases took place near the captive-rearing aviaries (1993-1995), assuming that birds would disperse to the various subpopulations. Since 1996, in an attempt to augment specific subpopulations and to balance sex ratios, releases have taken place within manageable areas occupied by the subpopulations, i.e. accessible areas where predator control can be carried out. Birds were not held on site before being released but, since 1999, food was provided at all release sites and for both age classes for 6 weeks to 2 months post-release, with the aim of easing the transition to the wild and encouraging site fidelity. All release sites contained good habitat for kaki in the form of riverbed, ponds, river delta and combinations of these habitats. Both Pierce (1982) and Sanders (1996) have examined food abundance for kaki across sites and found that although kaki breeding sites are in places with $>1 \mathrm{~g} \mathrm{~m}^{-2}$ dry matter of invertebrates, successful foraging occurs across areas where there is little detectable food. They are generalist, opportunist feeders and will take a wide variety of invertebrates depending on availability. The very low density of kaki (a total wild population of c. 87 birds) means there is no competition for food.

Since 1993 there have been 12 annual releases of subadults ( 314 birds) into seven sites and six annual releases of juveniles into four sites ( 150 birds). Released birds were colour banded and prior to 2002 carried tail-mounted radio transmitters with a 13 -week life: they were mostly located at least daily. After 6 weeks, both visual checks and radio-fixes were less frequent (more during breeding and fewer in winter). The same amount of effort was spent searching in all areas of stilt habitat each year by an experienced team of observers (with one observer participating in all years of checks), with no gaps in monitoring effort. Detectability is 
TABLE 1 Numbers of juvenile and subadult kaki released, alive 2 months and 2 years after release, consistently observed at the release site 2 months and 2 years after release, and consistently recorded at a useful site 2 years after release. Percentages are of the total alive after 2 months and 2 years.

\begin{tabular}{lllllll}
\hline & $\begin{array}{l}\text { Number } \\
\text { released }\end{array}$ & $\begin{array}{l}\text { Alive at } \\
2 \text { months }\end{array}$ & $\begin{array}{l}\text { Release site } \\
\text { at 2 months } \\
(\mathrm{n}, \%)\end{array}$ & $\begin{array}{l}\text { Alive at } \\
2 \text { years }\end{array}$ & $\begin{array}{l}\text { Release site } \\
\text { at 2 years } \\
(\mathrm{n}, \%)\end{array}$ & $\begin{array}{l}\text { Useful site } \\
\text { at 2 years } \\
(\mathrm{n}, \%)\end{array}$ \\
\hline Juvenile & 150 & 91 & $80(87.9)$ & $30^{*}$ & $19(63.3)$ & $25(83.3)$ \\
Subadult & 314 & 212 & $209(98.6)$ & $41^{*}$ & $29(70.7)$ & $36(87.8)$ \\
\hline
\end{tabular}

*25 juveniles and 52 subadults had not yet reached 2 years of age

very high. Kaki forage almost exclusively on water in open riverbed and wetland sites where vegetation is low or absent. Kaki plumage is starkly contrasted against their environment, and they are usually conspicuous in their behaviour. There are no recorded differences in foraging behaviour between juveniles, subadults and non-breeding adults. Breeding adults are conspicuous and often approach observers entering their territory. With the exception of one to two birds in a few years, the entire world population of kaki is individually tagged with colour rings. Kaki have high mate fidelity and non-tagged birds are usually identifiable within a season when they are with a known tagged mate. Within a few surveys of a site observers obtain a full list of individuals that rarely changes in subsequent visits. Observer knowledge of sites used by kaki is high and based on 27 years of recorded locations and regular surveys of similar habitats without kaki in the region. For these reasons we are confident that there is no bias as a result of detectability. Few birds were recovered dead; most went missing. Birds are classified as long-term missing if they have not been seen for $>12$ months and they are almost certainly dead: in these analyses, they are presumed dead.

\section{Data and analyses}

We used Ranges 6 (Kenward et al., 2003) to calculate distances moved between consecutive sightings and distance moved away from the release site. Distances moved between consecutive sightings ranged from small $\left(<_{1} \mathrm{~km}\right)$ to large $(>100 \mathrm{~km})$. Dispersal was quantified in three ways: (1) the proportions of distances moved by each bird between consecutive sightings that were short $(0-1 \mathrm{~km})$, medium $\left(>_{1-10} \mathrm{~km}\right)$ and long $\left(>_{10} \mathrm{~km}\right) ;(2)$ the maximum distance moved away from the release site, and (3) the number of subpopulations kaki were recorded at. In addition, age at release of individuals making moves $>25 \mathrm{~km}$ (and therefore outside the subpopulation they were intended to augment) was compared. Both proportions of moves and maximum distances were examined within 2 months following release, when birds were expected to be influenced more by release-site features. To standardize the opportunity for movement only those birds surviving the initial 2 months were included in this analysis. Because juveniles were only released from 1999, and supplementary feeding also began in this year, birds released before this year were also excluded from the data set, as were birds that made $<10$ moves. This left 73 juveniles and 96 subadults.

We then examined movements over the entire period birds were monitored, when birds were living independently of supplementary food and expected to be unaffected by release-site features. Because the length of the entire monitoring period varied depending on when birds died or disappeared, we restricted this analysis to birds that were still alive at 2 years of age but included those released before 1999, to improve sample size, because few individuals reach 2 years of age. Changing release-site protocols were less likely to affect the behaviour of birds over a 2-year period. This left 28 juveniles and 43 subadults. Although these birds survived for variable lengths of time after 2 years, linear regression showed no relationship between the length of time birds survived and the distance moved from their release site $\left(F_{1,63}=0.669, \mathrm{P}=0.416, R^{2}\right.$ adj. $\left.=-0.005\right)$. Sex was known for only a subsample of the birds released and was not included in the models.

We used general linear models (using SPSS $x$ v. 15; SPSS, Chicago, USA) to identify whether release age influenced dispersal: release group size and the size of the wild population at the release site at the time of release were entered as covariates. All values were transformed to verify assumptions of normality. Frequency distributions of covariates for juveniles and subadults were graphed to verify the assumption that the covariate has the same distribution for both groups (Quinn \& Keough, 2002), and there was substantial overlap. Interactions between release age and each of the covariates were examined to test for homogeneity of slopes (Quinn \& Keough, 2002): all interactions were non-significant except one. Independent $t$ tests were used to compare the number of moves made by juveniles and subadults, and a $\chi^{2}$ test was used to compare the proportions of juveniles and subadults making long-distance moves of $>100 \mathrm{~km}$.

\section{Results}

Proportions of short-, medium- and long-distance moves

Released kaki were located on average 33.6 times during the 2-month post-release period $(n=169, S E=0.98$; Fig. 2 a) 

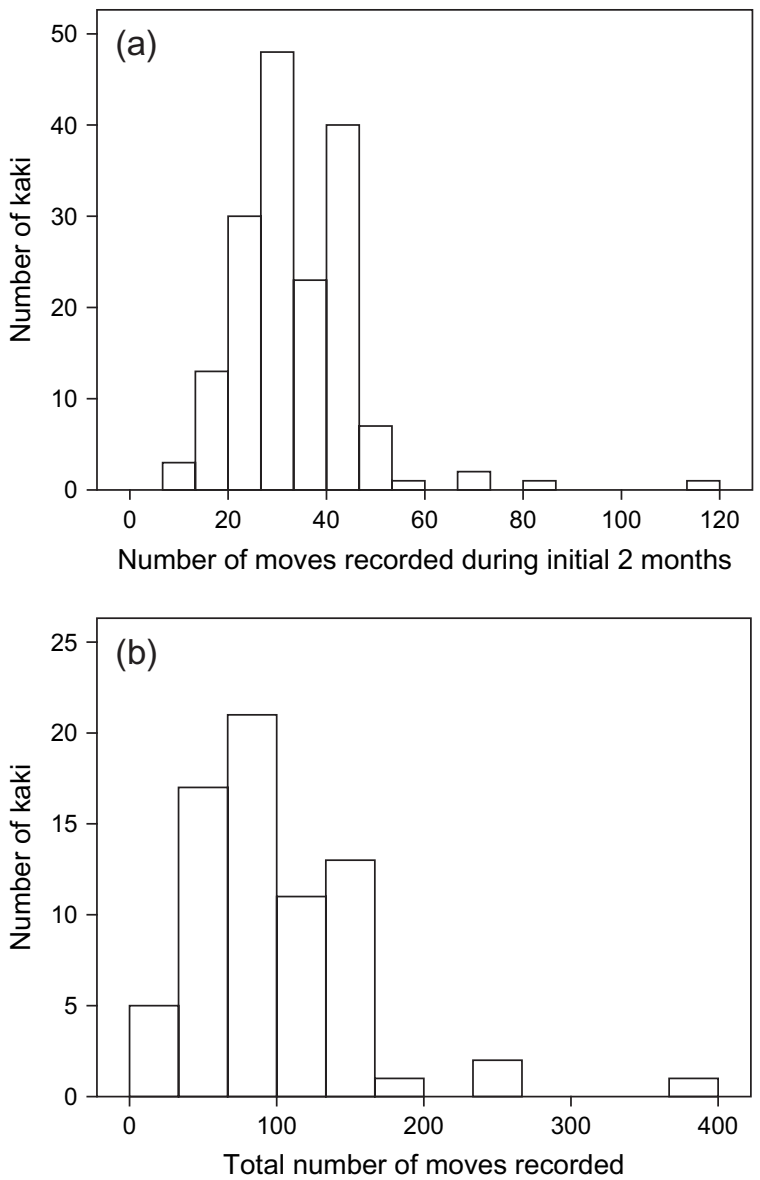

FIG. 2 Number of moves by kaki recorded for those birds that survived the initial 2 months post-release (a) and for those that survived at least 2 years (b).

and 52.9 times over the entire monitoring period $(n=182$, $\mathrm{SE}=2.25$; Fig. $2 \mathrm{~b}$ ). There was no difference between juveniles and subadults in the number of locations during either time period (2-month: $t=-1.372, \mathrm{df}=167, \mathrm{P}=0.172$; entire: $t=-0.683, \mathrm{df}=180, \mathrm{P}=0.495)$.

During the initial 2 months after release, subadults made proportionately more short-distance moves $(0-1 \mathrm{~km})$ than juveniles (subadults: mean $=0.960 \pm \mathrm{SE}$ 0.009; juveniles: mean $=0.920 \pm$ SE $\left.0.011 ; F_{1,176}=20.284, \mathrm{P}<0.001\right)$, whereas juveniles made proportionately more medium-distance moves $(0-10 \mathrm{~km})$ than subadults (subadults: mean $=0.040 \pm \mathrm{SE}$ 0.007; juveniles: mean $=0.070 \pm$ SE $0.011 ; F_{1,176}=7.764, \mathrm{P}=$ 0.006 . There was no difference between juveniles and subadults in the proportions of long-distance moves $(>10 \mathrm{~km}$; $\left.F_{1,176}=0.698, \mathrm{P}=0.405\right)$. The size of the wild population was not a significant covariate for short $\left(F_{1,176}=0.759\right.$, $\mathrm{P}=0.385)$, medium $\left(F_{1,176}=1.945, \mathrm{P}=0.165\right)$ or long moves $\left(F_{1,176}=0.313, \mathrm{P}=0.576\right)$. Release group size was also nonsignificant (short moves: $F_{1,176}=1.597, \mathrm{P}=0.208$; medium moves: $\left.F_{1,176}=2.836, \mathrm{P}=0.094\right)$ but was significant for long moves $\left(F_{1,176}=7.556, \mathrm{P}=0.007\right)$.
Among kaki that survived for at least 2 years there was no difference in proportions of short, medium or long moves made by juveniles and subadults $\left(F_{1,66}=0.107, \mathrm{P}=0.745\right.$; $F_{1,66}=0.004, \mathrm{P}=0.950 ; F_{1,66}=0.173, \mathrm{P}=0.678$, respectively). Neither of the covariates release group size or size of the wild population had any effect on the proportions of distances moved (release group size, $F_{1,66}=1.643, \mathrm{P}=0.204 ; F_{1,66}=$ 1.806, $\mathrm{P}=0.184$; and $F_{1,66}=1.236, \mathrm{P}=0.252$; and size of wild population, $F_{1,66}=0.569, \mathrm{P}=0.453 ; F_{1,66}=0.007, \mathrm{P}=0.950$; and $F_{1,66}=1.333, \mathrm{P}=0.252$, for short, medium and long moves, respectively).

\section{Maximum distance moved from the release site}

The maximum distance moved by birds away from the release site during the initial 2 months post-release was influenced by release age (subadults: mean $=0.3490 \pm \mathrm{SE}$ $1.74 \mathrm{~km}$; juveniles: mean $=6.72 \pm \mathrm{SE} 1.08 \mathrm{~km} ; F_{1,137}=$ 28.309, $\mathrm{P} \leq 0.001)$ and size of the wild population $\left(F_{1,137}=\right.$ $4.497, \mathrm{P}=0.036)$ but not by release group size $\left(F_{1,137}=2.477\right.$, $\mathrm{P}=0.118)$. There was a significant interaction between age and release group size $\left(F_{2,136}=9.895, \mathrm{P}<0.001\right)$ but not between age and size of the wild population $\left(F_{2,137}=2.584\right.$, $\mathrm{P}<0.079$ ).

The maximum distance moved away from the release site by birds that survived 2 years or more was not influenced by age at release $\left(F_{1,66}=2.048, \mathrm{P}=0.157\right)$, and neither of the covariates had any significant effect (release group size, $F_{1,66}=0.617, \mathrm{P}=0.435$; size of wild population, $\left.F_{1,66}=0.726, \mathrm{P}=0.397\right)$.

\section{Movement patterns of released birds}

Released birds visited between one and four subpopulations, with juveniles and subadults equally likely to visit one or more sites $\left(\chi^{2}=2.29, \mathrm{df}=2, \mathrm{P}>0.05\right)$. Among survivors that reached breeding age $(n=71), 67.6 \%(n=48)$ were subsequently observed consistently within the general area of the release site and $85.9 \%(n=61)$ were consistently observed at a useful site, i.e. where there was an existing subpopulation and associated management for protection (Table 1). Among the birds that reached 2 years of age, juveniles and subadults were equally likely to be observed consistently back at their release sites $\left(\chi^{2}=0.444, \mathrm{df}=1, \mathrm{P}>0.05\right)$.

Fifty-four kaki made moves during the entire monitoring period that took them more than $25 \mathrm{~km}$ away from their release site and consequently out of the subpopulation they were intended to augment (Fig. 3). Among the birds that made the longest moves of $>100 \mathrm{~km}$, which would take them right out of the Waitaki Basin, there were more juveniles than subadults $\left(\chi^{2}=7.49, \mathrm{df}=2, \mathrm{P}<0.05\right)$. The 13 kaki that made moves $>100 \mathrm{~km}$ were released at five different locations and in 5 different years. 


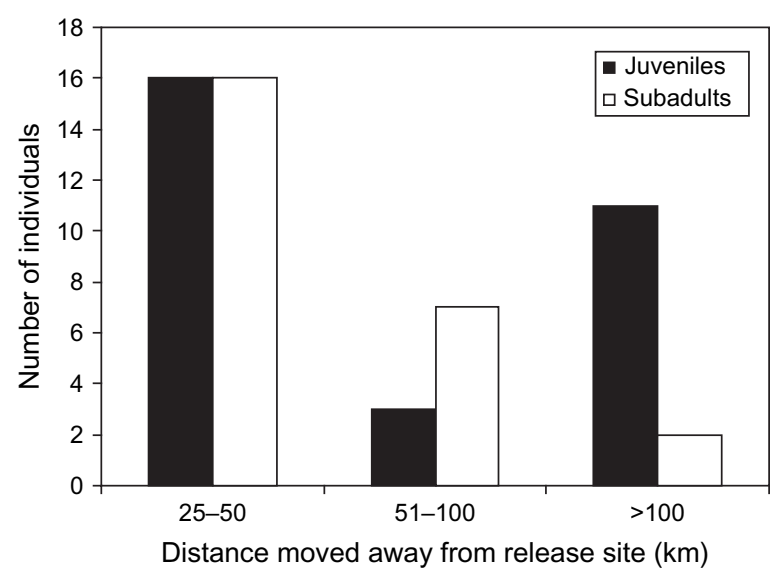

FIG. 3 Numbers of juvenile and subadult kaki moving at least $25 \mathrm{~km}$ away from their release site $(\mathrm{n}=54)$.

\section{Discussion}

Large movements by released kaki have been regarded as potentially problematic because such movements may not only take birds away from the subpopulations they were intended to augment but may also take them out of areas that are managed to promote their survival. One-third (32\%, juveniles and subadults combined) of released birds surviving until breeding age ended up in areas away from any of the five subpopulations and away from regular monitoring and protection from predators. Even if these individuals encounter other kaki and mate, in the absence of predator control and/or egg collection their breeding success is likely to be $<_{1} \%$ (Maloney \& Murray, 2001). In the absence of other kaki they may mate with pied stilts and produce hybrid offspring (Pierce, 1996). The size of the wild adult population of kaki is so small that any reduction in the number of breeding-age survivors moving away from manageable subpopulations would significantly improve viability, and a better understanding of why these birds move would improve the restoration outcome. Considerable individual variability can exist in dispersal behaviour (Doerr \& Doerr, 2005), with propensity to move depending on a suite of individual (age, sex, developmental stage and physiological condition), social and environmental factors (Stenseth \& Lidicker, 1992; Clarke et al., 1997; Alonso et al., 1998; Serrano et al., 2003; Snoeijs et al., 2004; Haag et al., 2005; Aragón et al., 2006; Martin et al., 2008). Release protocols can also influence subsequent movements (Hardman \& Moro, 2006).

Among kaki $47.5 \%$ of juveniles and $35 \%$ of subadults moved between subpopulations in the Waitaki Basin at least once and up to three times. Age at release was a strong predictor of propensity to make longer movements during the first 2 months post-release, with juvenile kaki making moves that were longer than subadult moves and that took them furthest away from their release sites. Age has been identified as an important factor influencing movements of a number of reintroduced species. Threatened Hawaiian stilts Himantopus mexicanus knudseni showed age-dependent movements; the proportion of birds seen outside their natal wetland decreased with age from $66 \%$ moving between hatching and the next breeding season to $30 \%$ moving as third-year birds (Reed et al., 1998). Translocated adult female red-cockaded woodpeckers Picoides borealis made fewer moves outside the release site than subadult females, leading to the suggestion that removing subadult females from the translocation would have minimal impact on the donor clan and would maximize the value of individuals that otherwise might not survive (Allen et al., 1993). The recovery of purple swamphen Porphyrio porphyrio populations appears to be dependent on, among other things, the species' ability to disperse long distances and colonize new habitats, with juvenile birds playing an important role as long-distance colonists (SanchezLafuente et al., 2001). However, among mammals, younger individuals were less inclined to move. Translocated adult and yearling elk Cervus elaphus moved further than calves (Larkin et al., 2004). Survival and reproductive success of swift fox $V$. velox were higher for those with small dispersal distances, and because translocated juveniles moved least, they were considered to be most appropriate for establishing foxes in small protected areas (Moehrenschlager \& Macdonald, 2003). Translocated adult grey wolf $C$. lupus left release areas more quickly than pups (Fritts et al., 1984).

All released kaki were collected as eggs, captive reared and released at various locations. Juveniles were released at an age when they would normally still be accompanying their parents. In the absence of a stabilizing family group, juveniles may make larger movements. The high degree of mobility indicates connectivity between subpopulations, at least by young birds: there is a low likelihood of movements between subpopulations by adults (Sanders, 1996).

The value of long-term monitoring of released individuals is clear for kaki because initial differences between juveniles and subadults in lengths of movements did not appear to affect the proportions of birds returning to their release location 2 years later, at breeding age. If post-release monitoring was short-term the tendency for juveniles to make more medium-length moves and end up further from the release site would have been cause for concern and could prompt a change of strategy towards releasing only subadults. This in turn would limit the number of individuals able to be released. Longer term monitoring allowed confirmation that regardless of whether a bird was released as a juvenile or subadult, there was a similar likelihood that it would survive and end up near the release site by breeding age.

Social factors influence movement behaviour. In great bustards Otis tarda an inverse relationship between the probability of dispersal and the size of the natal group was attributed to the presence and abundance of conspecifics, 
possibly providing cues to habitat quality (Martin et al., 2008). In translocation projects the role conspecifics play may be slightly different from those hypothesized for healthy unmanipulated populations. Translocations typically occur when population sizes are very small and there is little or no competition for resources or mates. The presence of wild conspecifics can promote higher release-site fidelity among captive-bred and released birds, with resident birds providing the necessary social interactions to stimulate released individuals to remain in the area and obtain mates (Carrie et al., 1999; Tweed et al., 2003). For example, translocations of intact colonies of the highly social black-eared miner Manorina melanotis promoted site fidelity and social cohesion (Clarke et al., 2002). Kaki released at sites with larger wild populations moved less far from the site during the first 2 months than birds released at sites with small wild populations (Fig. 4), suggesting that the presence of conspecifics promoted site fidelity. The significant relationship between release group size and longer movements suggests that larger groups may be associated with a higher likelihood of making larger moves; however, the wide scatter of points indicates that this is not
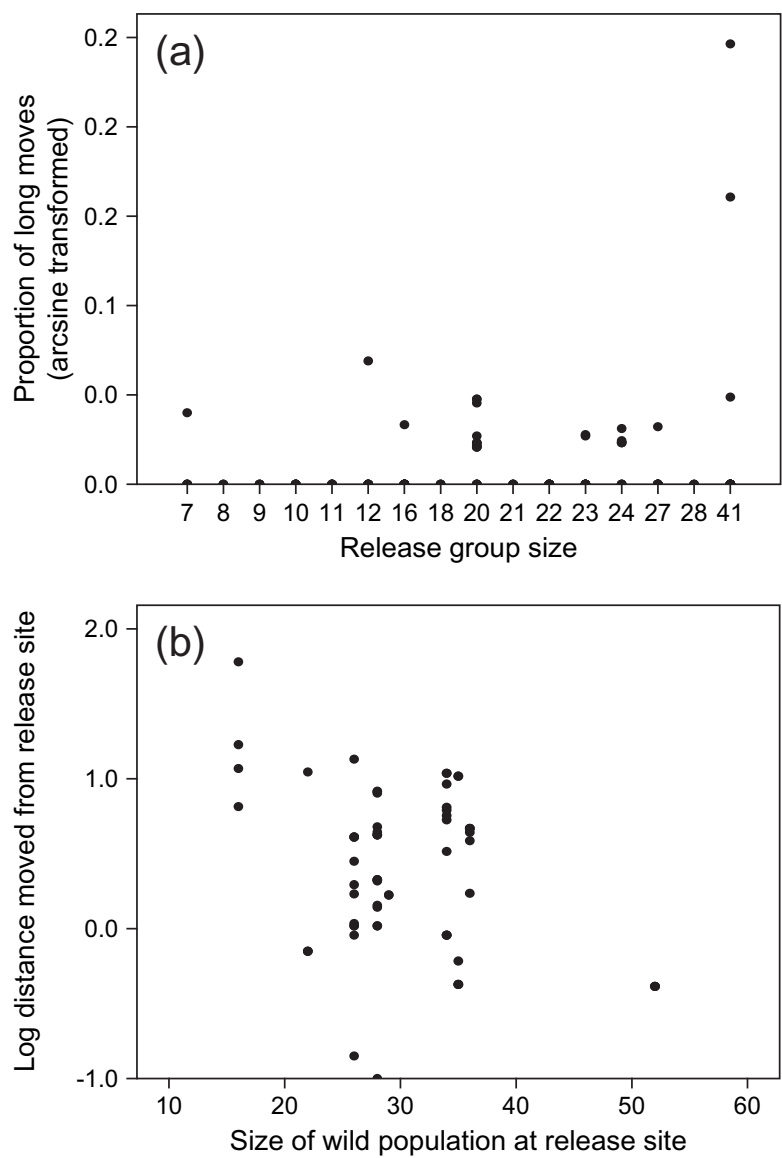

FIG. 4 Relationship between (a) proportion of long-distance moves $(>10 \mathrm{~km})$ and release group size, and (b) maximum distance moved from the release site in the first 2 months post-release and size of the wild population. a tight relationship (Fig. 4). Larger release groups could result in more competition for food at the release sites, and possibly more aggressive interactions at the feeding plates, which could motivate some birds to leave the area. In addition, the one significant interaction suggested that release age may have influenced the relationship between the maximum distance moved from the release site and the group size.

Data collected during post-release monitoring of reintroductions and supplementations should enable assessment of project success but also test the validity and efficacy of translocation methods (Sarrazin \& Legendre, 2000). There has been improvement in the extent of monitoring of translocations; however, most research, including this study, is retrospective (Seddon et al., 2007) and much monitoring is relatively short-term. Short-term post-release monitoring can give rise to an incomplete understanding of translocation outcomes and lead to unwarranted project abandonment or unnecessary adjustment of release protocols. In the case of the kaki, results from monitoring occurring over a few months post-release would have suggested that subadults be released in preference to juveniles, which would have reduced the total output from the captive breeding programme. On the other hand, data sets from long-term monitoring can be large, contain a lot of superfluous data and be inadequate to answer specific questions. Adopting an experimental approach from the outset can save considerable time if practitioners wish to understand release dynamics. Threatened species projects can benefit from adopting an experimental approach and should explicitly factor propensity to move into strategies involving selection of birds for release.

\section{Acknowledgements}

We thank the kaki recovery team and the Department of Conservation field staff for their efforts in releasing and locating kaki, run-holders for access to their properties, the Isaacs Wildlife Trust for support in kaki captive breeding, Brian Niven for statistical advice and several anonymous reviewers.

\section{References}

Allen, D.H., Franzreb, K.E. \& Escano, R.E.F. (1993) Efficacy of translocation strategies for red-cockaded woodpeckers. Wildlife Society Bulletin, 21, 155-159.

Alonso, J.C., Martin, E., Alonso, J.A. \& Morales, M.B. (1998) Proximate and ultimate causes of natal dispersal in the great bustard Otis tarda. Behavioral Ecology, 9, 243-252.

Aragón, P., Meylan, S. \& Clobert, J. (2006) Dispersal statusdependent response to the social environment in the common lizard, Lacerta vivipara. Functional Ecology, 20, 900-907.

Carrie, N.R., Conner, R.N., Rudolph, D.C. \& Carrie, D.K. (1999) Reintroduction and post-release movements of red 
cockaded woodpecker groups in eastern Texas. Journal of Wildlife Management, 63, 824-832.

Clarke, R.H., Boulton, R.L. \& Clarke, M. (2002) Translocation of the socially complex black-eared miner Manorina melanotis: a trial using hard and soft-release techniques. Pacific Conservation Biology, 8, 223-234.

Clarke, M.F. \& Schedvin, N. (1997) An experimental study of the translocation of noisy miners, Manorina melanocephala and difficulties associated with dispersal. Biological Conservation, 80, 161-167.

Clarke, A.L., SÆther, B.-E. \& Roskaft, E. (1997) Sex biases in avian dispersal: a reappraisal. Oikos, 79, 429-438.

Doerr, E.D. \& Doerr, V.A.J. (2005) Dispersal range analysis: quantifying individual variation in dispersal behaviour. Oecologia, $14,1-10$.

Fancy, S.G., Snetsinger, T.J. \& Jacobi, J.D. (1997) Translocation of the palila, an endangered Hawaiian honeycreeper. Pacific Conservation Biology, 3, 39-46.

Fritts, S.H., Paul, W.J. \& Mech, L.D. (1984) Movements of translocated wolves in Minnesota. Journal of Wildlife Management, 48, 709-721.

Griffith, B., Scott, J.M., Carpenter, J.W. \& Reed, C. (1989) Translocation as a species conservation tool: status and strategy. Science, 245, 477-480.

HaAg, C.R., SaAstamoinen, M., Marden, J.H. \& Hanski, I. (2005) A candidate locus for variation in dispersal rate in a butterfly metapopulation. Proceedings of the Royal Society B, 272, 2449-2456.

Hardman, B. \& Moro, D. (2006) Optimising reintroduction success by delayed dispersal: is the release protocol important for hare-wallabies? Biological Conservation, 128, 403-411.

Holm, G.O., Hess, T.J., Justic, D., McNease, L., Linscombe, R.G. \& Nesbitt, S.A. (2003) Population recovery of the eastern brown pelican following its extirpation in Louisiana. Wilson Bulletin, 115, 431-437.

Ims, R.A. \& Hjermann, D.Ø. (2001) Condition dependent dispersal. In Dispersal (eds J. Clobert, E. Danchin, A.A. Dhondt \& J.D. Nichols), pp. 203-216. Oxford University Press, Oxford, UK.

IUCN (1998) IUCN Guidelines for Reintroductions. IUCN/SSC ReIntroduction Specialist Group, Gland, Switzerland.

Keedwell, R.J., Maloney, R.F. \& Murray, D.P. (2002) Predator control for protecting kaki (Himantopus novaezelandiae)-lessons from 20 years of management. Biological Conservation, 105, 369-374.

Kenward, R.E., South, A.B. \& W Alls, S.S. (2003) Ranges 6 vi.2. For the Analysis of Tracking and Location Data. Online Manual. Anatrack Ltd, Wareham, UK.

Kramer-Schadt, S., Revilla, E., Wiegand, T. \& BreitenMOSER, U. (2004) Fragmented landscapes, road mortality and patch connectivity: modelling influences on the dispersal of Eurasian lynx. Journal of Applied Ecology, 41, 711-723.

Larkin, J.L., Cox, J.J., Wichrowski, M.W., Dzialak, M.R. \& MAEHR, D.S. (2004) Influences on release-site fidelity of translocated elk. Restoration Ecology, 12, 97-105.

Maloney, R.F. \& Murray, D.M. (2001) Kaki (Black Stilt) Recovery Plan. Unpublished Report. Department of Conservation, Wellington, New Zealand.

Martin, C.A., Alonso, J.C., Alonso, J.A., Palacin, C., Magaña, M. \& MARTin, B. (2008) Natal dispersal in great bustards: the effect of sex, local population size and spatial isolation. Journal of Animal Ecology, 77, 326-334.

Matson, T.K., Goldizen, A.W., Jarman, P.J. \& Pople, A.R. (2006) Dispersal and seasonal distributions of black-faced impala in the Etosha National Park, Namibia. African Journal of Ecology, $44,247-255$.
Miller, B., Ralls, K., Reading, R., Scott, J. \& Estes, J. (1999) Biological and technical considerations of carnivore translocation: a review. Animal Conservation, 2, 59-68.

Moehrenschlager, A. \& Macdonald, D.W. (2003) Movement and survival parameters of translocated and resident swift foxes Vulpes velox. Animal Conservation, 6, 199-206.

Pierce, R.J. (1982) A comparative ecological study of pied and black stilts in south Canterbury. PhD thesis, University of Otago, Dunedin, New Zealand.

PierCe, R.J. (1996) Ecology and management of the black stilt Himantopus novaezelandiae. Bird Conservation International, 6, $81-88$.

Quinn, G.P. \& Keough, M.J. (2002) Experimental Design and Data Analysis for Biologists. Cambridge University Press, Cambridge, UK.

Reed, J.M., Silbernagle, M.D., Evans, K., Engilis, A., Jr. \& OrING, L.W. (1998) Subadult movement patterns of the endangered Hawaiian stilt (Himantopus mexicanus knudseni). Auk, 115, 791-797.

Sanchez-Lafuente, A.M., Valera, F., Godino, A. \& Muela, F. (2001) Natural and human-mediated factors in the recovery and subsequent expansion of the purple swamphen Porphyrio porphyrio L. (Rallidae) in the Iberian Peninsula. Biodiversity and Conservation, 10, 851-867.

S ANDERS, M.D. (1996) Effects of fluctuating lake levels and habitat enhancement on black stilts (Himantopus novaezelandiae Gould, 1841). PhD thesis, University of Canterbury, Christchurch, New Zealand.

Sarrazin, F. \& Legendre, S. (2000) Demographic approach to releasing adults versus young in reintroductions. Conservation Biology, 14, 488-500.

Schiegg, K., Daniels, S.J., Walters, J.R. \& Priddy, J.A. (2006) Inbreeding in red-cockaded woodpeckers: effects of natal dispersal distance and territory location. Biological Conservation, 131, 544552.

Seddon, P.J. (1999) Persistence without intervention: assessing success in wildlife interventions. Trends in Ecology \& Evolution, $12,503$.

Seddon, P.J., Armstrong, D.P. \& Maloney, R.F. (2007) Developing the science of reintroduction biology. Conservation Biology, 21, 303-312.

Serrano, D., Tella, J., Donázar, J.A. \& Pomarol, M. (2003) Social and individual features affecting natal dispersal in the colonial lesser kestrel. Ecology, 84, 3044-3054.

Skjelseth, S., Ringsiy, T.H., Tufto, J., Jensen, H. \& Sether, B.-E. (2007) Dispersal of introduced house sparrows Passer domesticus: an experiment. Proceedings of the Royal Society B, 274, 1763-1771.

Snoeijs, T., Van de Casteele, T., Adriaensen, F., Matthysen, E. \& Eens, M. (2004) A strong association between immune responsiveness and natal dispersal in a songbird. Proceedings of the Royal Society London B, 271(Suppl.), S199-S201.

Stenseth, N.C. \& Lidicker, Jr, W.Z. (1992) The study of dispersal: a conceptual guide. In Animal Dispersal: Small Mammals as a Model (eds N.C. Stenseth \& W.Z. Lidicker, Jr), pp. 1-16. Chapman \& Hall, London, UK.

Trakhtenbrot, A., Nathan, R., Perry, G. \& Richardson, D.M. (2005) The importance of long-distance dispersal in biodiversity conservation. Diversity and Distributions, 11, 173-181.

Tweed, E.J., Foster, J.T., Woodworth, B.L., Oesterle, P., Kuehler, C., Lieberman, A.A. et al. (2003) Survival, dispersal and home-range establishment of reintroduced captive-bred puaiohi, Myadestes palmeri. Biological Conservation, 111, 1-9. 
Van Vuren, D., Kuenzi, A.J., Loredo, I., Leider, A.L. \& Morrison, M.L. (1997) Translocation as a non-lethal alternative for managing California ground squirrels. Journal of Wildlife Management, 61, 351-359.

\section{Biographical sketches}

Yolanda van HeEZiK has studied pre-release and post-release performance of captive-bred animals in population restorations and is currently researching urban wildlife. RichaRD MALONey has been working on the recovery of threatened species for the last 21 years. His current work is developing prioritization tools to ensure cost-effective recovery for all of New Zealand's threatened species. PHILIP SEDDON is Director of the Wildlife Management Programme at the University of Otago, where his research interests include the restoration and conservation management of native species in New Zealand. He is the current chair of the Bird Section of the IUCN/SSC Reintroduction Specialist Group. 